\title{
Co removal and phase transformations during high power diode laser irradiation of cemented carbide
}

\author{
${ }^{1}$ Barletta M., ${ }^{1}$ Rubino G., ${ }^{2}$ Gisario A. \\ ${ }^{1}$ Dipartimento di Ingegneria Meccanica, Università degli Studi di Roma Tor Vergata, Via del \\ Politecnico, 1 - 00133 Roma (I) \\ ${ }^{2}$ Dipartimento di Meccanica ed Aeronautica, Università degli Studi di Roma La Sapienza, Via \\ Eudossiana, 18 - 00184 Roma (I)
}

\begin{abstract}
.
The use of a continuous wave-high power diode laser for removing surface Co-binder from Cocemented tungsten carbide (WC-Co (5.8\% wt.)) hardmetal slabs was investigated. Combined scanning electron microscopy, energy dispersive X-ray spectroscopy and X-ray diffraction analyses were performed in order to study the phase transformations and micro-structural modifications of the WC-Co substrates occurring during and after laser irradiation. The micro-structure of the WCCo progressively transforms as energy density increased, exhibiting stronger removal of $\mathrm{Co}$ and WC grain growth. At very high energy density, local melting of the WC grains with the formation of big agglomerates of interlaced grains is observed, and the crystalline structure of the irradiated substrate shows the presence of a brittle ternary eutectic phase of W, Co and C (often referred to as the $\eta$-phase). The latter can be detrimental to the mechanical properties of WC-Co. Therefore, the proper adjustment of the laser processing parameters plays a crucial role in surface treatments of WC-Co substrates prior to post-processing like diamond deposition.
\end{abstract}

Key Words: Diode Laser, Surface Treatments, Hardmetal, Cobalt. 


\section{Introduction}

Co $(5.8 \%$ wt.)-cemented tungsten carbides belong to the class of hard metals and they are widely used for the manufacturing of cutting tools, sliding bearings, drawing dies and a large variety of wear-resistant components [1]. Coating hard metals with superhard materials like diamond is therefore of utmost interest as it can further extend the useful lifespan of such components [210]. Yet, the deposition of diamond coatings onto WC-Co can be extremely complicated as a result of poor adhesion. This can be essentially ascribed to: (i) the mismatch in thermal expansion coefficients between diamond and WC-Co, which, at the typical high temperatures inside the chemical vapor deposition (CVD) chamber, generates large residual stresses at the interface; (ii) the role of surface Co inside the WC-Co matrix during diamond CVD, which promotes carbon dissolution and diffusion [11-17]. Therefore, the interfacial Co must be effectively removed from the WC-Co substrate for the deposition of highly adherent diamond coatings.

There are different ways by which WC-Co substrates can be treated and have their surface Co removed, although the most widespread techniques can be summarized as follows: (i) Co etching, in which aqueous solutions of either strong oxyacids or hydrochloric acid, as well as more complex multi-step etching procedures, etch the Co out of the outermost layers of WC-Co. This, sometimes, also corrugates the WC grains [18-26]; (ii) use of intermediate layers of various materials (amorphous carbon, metallic $\mathrm{Cr}$, $\mathrm{Ti}$, Ta, etc. and ceramic $\mathrm{CrN}, \mathrm{TiC}, \mathrm{TiN}, \mathrm{SiC}, \mathrm{Si}_{3} \mathrm{~N}_{4}$ ) onto the WC-Co surface preventing Co and C diffusion [27-34]. In addition, interlayers can be designed to adjust the thermal expansion coefficients between WC-Co and diamond, thus reducing thermal residual stresses inside the diamond coating during CVD [35-36]; (iii) mechanical treatments, in which mechanical interlocking between diamond and WC-Co is promoted by micro- or macrocorrugating WC-Co or the interlayer surface [36-38]. These mechanical treatments mostly follow the chemical etching and/or application of intermediate layers; (iv) WC-Co thermal or thermochemical treatments, reducing interfacial Co concentration, inducing surface reconstruction of the WC-Co substrate and a modification of surface morphology and microstructure [39-43].

Singh et al. and, subsequently, Li et al. proposed the use of a pulsed laser to reduce the Co concentration at the WC-Co surface, induce its corrugation and, therefore, promote the adherent growth of CVD diamond coatings [44-46]. Nonetheless, the pulsed diode laser source was operated at a very high laser irradiance $\left(>80 \mathrm{MW} / \mathrm{cm}^{2}\right)$. Laser treatments led to remelting of the 
irradiated material and gave rise to a sort of complete surface reconstruction rather than to the removal of Co from the WC-Co surface [46]. The final result was a macro-corrugated morphology with rather flat peaks, essentially composed of WC, and hollow valleys in which some residual Co was still present. In addition, some Co and W oxides could be easily generated at such a high processing temperature, if precautions to protect the WC-Co substrates from oxygen were not taken [46]. These results necessitated the combination of the pulsed laser source with further chemical treatments like etching with dilute acid solutions to remove the excess in Co and, eventually, most of the oxides, thus reducing the potentiality, safety and industrial suitability of the technique $[44,46]$.

In this respect, the present work moves to: (i) investigate an unprecedented laser treatment of the WC-Co substrate, namely to remove the interfacial Co-binder with a continuous wave high power diode laser source and without any need for further pre-treatments of the substrate; (ii) promote the establishment of an outermost layer onto the WC-Co, rich in WC, and thus with thermal properties and, in particular, with a thermal expansion coefficient that are closer to diamond; (iii) study the evolution of the WC-Co micro-structure under laser treatments, aimed at contributing to the final performance of the diamond-coated substrate. 


\section{Experimental}

Grinded substrates of WC-5.8wt.\%Co of size $10 \times 10 \times 3 \mathrm{~mm}^{3}$ (Fabbrica Italiana Leghe Metalliche Sinterizzate SpA, Anzola d'Ossola) with an average grain size of $0.7-0.8 \mu \mathrm{m}$, a hardness of 90.0 HRA and $2900 \mathrm{MPa}$ transverse rupture strength (TRS, according to ISO 3327) were irradiated by a 940 $\mathrm{nm}$ continuous wave-high power diode laser (cw-HPDL). In order to prevent Co and W oxidation, the samples were placed in an aluminium chamber flushed with pure $\operatorname{Ar}(99.999 \%)$. A glass window at the top of the chamber allowed delivery of laser irradiation and inspection. Laser power was set in the range of 600 to $1500 \mathrm{~W}$ and scan speed was always kept constant at $1 \mathrm{~mm} / \mathrm{s}$. Experimental tests were performed by focusing the laser beam through a $63 \mathrm{~mm}$ long focus lens, giving rise to an elliptical spot of $3.8 \times 1.2 \mathrm{~mm}$ at the sample surface. The beam was moved back and forth along three linear and parallel patterns to uniformly cover the entire substrate surface with an overlap of $0.7 \mathrm{~mm}$ between two consecutive linear patterns. The total sample treatment lasted about $1 \mathrm{~min}$. For comparative purposes, as-ground WC-Co substrates submitted to a twostep chemical etching (Murakami's - Peroxide MP treatment) were also investigated. MP is a wellknown two-step chemical pre-treatment [23], widely used to improve diamond adhesion on WCCo substrate. During MP, the WC-Co substrate was first etched for 15 min with Murakami's reagent (10 $\mathrm{g} \mathrm{K}_{3}\left[\mathrm{Fe}(\mathrm{CN})_{6}\right]+10 \mathrm{~g} \mathrm{KOH}+100 \mathrm{ml}$ of water) to corrugate the WC-grains. Then, WC-Co was etched again with Caro's acid ( $3 \mathrm{ml} 96 \mathrm{wt} . \% \mathrm{H}_{2} \mathrm{SO}_{4}+88 \mathrm{ml} 30 \% \mathrm{w} / \mathrm{v} \mathrm{H}_{2} \mathrm{O}_{2}$ ) for $10 \mathrm{~s}$ for removing the Co binder.

Field emission gun scanning electron microscopy (FEG-SEM, LEO model Supra 35) and energy dispersive X-ray spectroscopy (EDXS, Oxford Instruments Ltd., model Inca 300) were used to investigate the changes in the morphology and perform preliminary chemical analyses of the WCCo substrates before and after laser treatments. Their roughness was measured by a contact gauge surface profiler (Taylor Hobson Surface Topography System TalySurf CLI 2000). 100 surface profiles with a lateral spacing of $10 \mu \mathrm{m}$ and with a resolution of $0.5 \mu \mathrm{m}$ were recorded. A very low scan speed of $50 \mu \mathrm{m} / \mathrm{s}$ was adjusted during the measurements in order to minimize the sliding speed of the stylus tip onto the WC-Co substrate and ensure measurement accuracy. TalyMap software Release 3.1 was used for data analysis and image processing. The micro-structure and phase transformations of the WC-Co substrates before and after laser treatments were characterized by the grazing incidence $\left(\omega=3^{\circ}\right)$ and $\theta / 2 \theta$ X-ray diffraction (XRD) with a Philips $X^{\prime}$ Pert Pro diffractometer, equipped with a plane mono-chromator using Cu K $\alpha$ radiation $(\lambda=1.5418 \AA$ ). 


\section{Results and discussion}

\subsection{Analysis of surface morphology}

Surface morphology of the WC-Co substrates by varying the laser power are shown in Fig. 1a-1i. Figure 1a shows the morphology of the as-received WC-Co substrate. The morphology is rather smooth with some grinding marks. WC grains are not visible, as dipped inside the Co matrix. Fig. 1b-1i reports the morphology of the WC-Co substrates after laser processing, increasing power in the range of 600 to $1400 \mathrm{~W}$. As the laser power is increased, the surface morphology of the WC-Co samples becomes rougher. This is the result of the Co removal and WC grains, progressively protruding out from the substrate. The roughening of the surface profiles can be seen in Fig. 2, where the presence of four scenarios can be emphasized: (i) the as-received WC-Co (i.e., untreated sample), characterized by a smooth surface profile; (ii) WC-Co after laser treatments at low power (i.e., under-treated samples, 600-1100 W), in which a slight corrugation due to the selective removal (that means, only from the outermost layer of the substrate) of Co can be observed; (iii) WC-Co samples after laser treatments at intermediate power (i.e., properly-treated samples, 1200-1400 W), in which a significant corrugation due to the protrusion of the WC grains from the substrate deprived of Co binder is visible; (iv) WC-Co samples after laser treatment at high power (i.e., over-treated samples, $1500 \mathrm{~W}$ ), characterized by an uneven morphology composed of large peaks and deep valleys. The surface profile after MP treatments is reported in Fig. 2, as well. MP treatment generates a corrugation close to the one achieved after laser treatments at low (600-1100 W) and, above all, intermediate power (1200-1400 W). Fig. 3 reports the corresponding average roughness $R_{a} . R_{a}$ progressively increased with laser power, thus identifying four scenarios: (i) the untreated WC-Co sample characterized by a $R_{a}<0.03 \mu \mathrm{m}$; (ii) the under-treated samples (600-1100 W), with $R_{a}$ increasing from 0.03 to nearly $0.05 \mu \mathrm{m}$; (iii) the properly-treated samples (1200-1400 W) with $R_{a}$ from 0.05 to $0.06 \mu \mathrm{m}$; (iv) and the over-treated $(1500 \mathrm{~W})$ sample characterized by $R_{a}$ of $\sim 0.15 \mu \mathrm{m}$. $R_{a}$ of the MP-treated sample is $\sim 0.05 \mu \mathrm{m}$, very close to the one achieved by WC-Co after laser treatments at low and intermediate power. Fig. 4 summarizes the evolution of the surface morphology. The as-received WC-Co substrate shows a defective morphology characterized by the presence of local tears and cracks due to the grinding process. The grinding process tends to plastically deform the ductile Co binder, which spreads over the sample surface covering the underlying WC grains. During grinding, the Co binder is severely damaged by the abrasive tools, which produce small tears and cracks over the material 
(Fig. 4a). Fig. 4b reports the morphology of an under-treated sample (600-1000W). There is a remarkable micro-corrugation due to the removal of $\mathrm{Co}$, thus explaining the increase in average roughness from less than 0.03 to $0.04-0.05 \mu \mathrm{m}$. WC grains starts to become visible, although still partially dipped inside the Co binder. They are mostly polygonal with sharp edges and still have an average size of 0.7-0.8 $\mu \mathrm{m}$. Nonetheless, some bigger sized grains of different shapes can be noticed. Some polygonal carbide grains turned into long grains (> $1 \mu \mathrm{m})$, whilst some over-sized (2-3 $\mu \mathrm{m})$ 'triangular' grains are visible, too. Such occasional grain enlargement can be ascribed to local heating of the laser-processed WC grains. However, the edges of the over-sized grains retained their sharpness, evidence of the lack of any melting phenomenon.

The reason why Co is selectively removed and WC grains slightly affected after laser treatments at low power can be ascribed to the difference in the melting and boiling temperatures of Co and WC and to their absorption coefficients (Table 1). The melting and boiling points of Co are 1768 and $3200 \mathrm{~K}$, respectively, while the melting and boiling points of WC are 3243 and $6273 \mathrm{~K}$. In the nearinfrared region, the absorption coefficient of WC is about 0.8 , whilst the absorption coefficient of Co is significantly lower (about 0.55 ), even lower than other metals like steel (about 0.7 ). When the laser beam irradiates the WC-Co, the WC is more prone to absorb energy and, then, release it to the surrounding Co. The WC grains can therefore approach very high temperatures. If enough energy is delivered towards the sample surface, the WC grains can locally reach temperatures high enough to induce local melting ejection and the vaporization of the surrounding Co, whilst the grains themselves can be only minimally affected. Finally, as the percentage of Co inside the investigated WC-Co is very limited (5.8 \% wt.), in the outermost layer of the substrate the Co is completely surrounded by the hotter WC grains, which provoke its fast removal. The Co binder will quickly evaporate or displace, leaving the WC grains sticking out of the surface, thus promoting the formation of several voids. At the high energy densities typical of laser processing, it is reasonable to argue that the WC-Co surface sharply rises to the maximum temperature and then quickly cools. The fast evaporation of Co induces further acceleration in the cooling process of WCCo. Under such a thermal cycle, the WC grains remain mostly unaffected provided that the laser processing is performed at low to moderate powers (600 to $1100 \mathrm{~W}$ ).

[1]Fig. 4c shows the surface morphology of a 'properly-treated' (1200-1400 W) sample. WC grains protrude from the outermost layers of the WC-Co, almost completely deprived of Co. The sample surface is still more corrugated, thus providing evidence of the average roughness increase to $0.05-0.06 \mu \mathrm{m}$ (Fig. 3). Most of the WC grains maintain their polygonal shape with sharp edges, 
although a general increase in the grain size can be observed. The size of the outermost grains falls into the range of 1-2 $\mu \mathrm{m}$ and they are superimposed on a deeper layer of smaller WC grains which, being less exposed to laser radiation, keep their original size $(<1 \mu \mathrm{m})$. Some WC grains start exhibiting incipient melting phenomena. They have rounder corners and tend to become interlaced, thus forming bigger agglomerates. Some brighter droplets can be seen on the surface of most of the WC grains (Fig. 5). From EDXS analysis (Fig. 6), they were found to be richer in W as result of WC decarburization. In fact, when WC-Co is treated at a high enough laser power, Co is completely removed from the outermost layers of material. The corresponding material surface is rich in protruding WC grains, which facilitate the absorption of a greater fraction of the incident laser power. This results in local excessive heating and partial melting of the WC particles. The local excessive heating or partial melting of WC grains induces carbon deficiency in WC-Co alloys due to precipitation of carbon as graphite:

$$
2 \mathrm{WC}=\mathrm{W}_{2} \mathrm{C}+\mathrm{C}
$$

thus forming $\mathrm{W}_{\mathrm{x}} \mathrm{C}_{\mathrm{y}}$ phases richer in $\mathrm{W}[48]$.

Fig. $4 \mathrm{~d}$ shows the surface morphology of an over-treated laser sample (1500 W). The morphology of WC-Co looks like melt-induced structures, with WC 'isles' (Fig. 6), protruding out from the core of the laser-treated material. The grains have less difference in height, although they have clear grain boundaries. The sharp corners of the WC grains disappeared and the microstructure of the surface was composed of interlaced large grains with round corners. An increase in WC grain size from $<1 \mu \mathrm{m}$ to $\sim 10 \mu \mathrm{m}$ is observed, too. Some round blowholes are visible on the irradiated surface area, the size of which are small. Such blowholes can probably be ascribed to degassing phenomena generated during laser processing. The sharp rise in $R_{a}$ of over-treated laser samples (Fig. 3) is, therefore, ascribable to the surface reconstruction of the WC-Co. This determines a coarsening of the morphology due to the formation of new resolidification structures. Moreover, when the laser power is increased to $1500 \mathrm{~W}$, a large amount of Co is quickly removed from the WC-Co surface. The resulting morphology is composed of micro-peaks corresponding to the WC grains still standing out from the WC-Co and micro-voids among them caused by the removal of Co. The micro-voids provide the opportunity for internal multiple laser beam reflections and laser energy is nearly entrapped at the outermost layers of the WC-Co. The melting of the WC and the 
re-crystallization process is significantly sped up, thus determining the formation of further enlarged gross WC grains, which contribute to the coarsening of the morphology.

Fig. 4e shows the morphology of the WC-Co after MP treatment. The morphology is not that different from the WC-Co morphology after laser treatments with the 'proper' parameters (1200$1400 \mathrm{~W})$. After MP treatment, the morphology is a superimposition of individually corrugated WC grains protruding from the core of WC-Co. This morphology is suitable for diamond deposition, being Co free and favouring mechanical interlocking between the coating and substrate as its coarseness.

\subsection{Analysis of surface morphology and thermal phenomena involved: comparison between diode} and pulsed laser sources

A comparison between the evolution of the WC-Co morphology after diode and pulsed laser processing can be performed [44-46]. There are significant differences in the setting of the operational parameters of the two techniques, which complicate the comparison. Diode laser is mostly operated in the irradiance range of 20 to $40 \mathrm{MW} / \mathrm{cm}^{2}$ (that is, 800 to $1400 \mathrm{~W}$ ) using a beam with a wavelength of $940 \mathrm{~nm}$. Pulsed lasers are operated from $80 \mathrm{MW} / \mathrm{cm}^{2}$ using a beam with a wavelength of $308 \mathrm{~nm}$. Therefore, the irradiance delivered to the samples by diode laser is definitely lower than the irradiance considered to be effective for a pulsed laser [44-46]. Such difference can be essentially ascribed to two concurrent reasons: (i) pulsed laser tends to ablate material from the WC-Co substrate and express the efficiency of treatment in terms of the thickness of removed material; (ii) pulsed laser is operated with a different beam with a shorter wavelength and, basically, with a high specific energy. As a result, pulsed lasers are able to deeply modify the WC-Co substrate, thus generating a new morphology constituted of rather flat peaks, mostly composed of WC, and hollow valleys richer in Co [44-46]. The surface of the WC-Co after pulsed laser treatments is severely altered and, often, completely remelted. This means that Co is not selectively removed, that is, the structure of WC inside the WC-Co is not left substantially unchanged whilst Co binder among them removed. To the contrary, pulsed laser treatments only allows the reconstruction of the surface morphology by progressively enlarging WC grains and remodelling the surface features by melting and resolidification process [44]. Further, they promote a reduction in Co concentration in the outermost layer of WC-Co substrate. However, this did not avoid to some Co to remain trapped inside the WC-Co and, eventually, recombine in other forms (oxides or carbide, [46]), potentially detrimental to the following processes. 
Although the reconstruction of the WC-Co is considered promising to improve the mechanical interlocking of an overlying coating [44-46], WC-Co laser-processed at such high energy density must be subsequently etched with an acid solution prior to diamond deposition to remove the excess of the Co binder and reduce the presence of $W$ and Co oxides developed at high temperature [45-46]. To the contrary, using the diode laser at proper energy density (30-40 $\mathrm{MW} / \mathrm{cm}^{2}$, that is, $1100-1400 \mathrm{~W}$ ) allows to selectively remove the Co binder, without largely affecting the WC grains (Figure 4c). Accordingly, the laser-treated surface is mostly Co-free, microcorrugated and without any large thermal alteration. This surface can be considered ready for diamond deposition without the need for any extra chemical treatment.

\subsection{Analysis of phase transformations}

The $\theta / 2 \theta$ (gonio) and grazing incidence $\left(\omega=3^{\circ}\right)$ XRD diffractograms vs. laser power are reported in Figs. 7-8. The as-received WC-Co sample shows only the presence of sharp WC and rather small Co peaks. With increasing laser power, the Co peaks tend to progressively decrease. The grazing incidence $\left(\omega=3^{\circ}\right)$ XRD spectra reported in Fig. 8 are representative of the material behaviour of the outermost layer of the WC-Co. They confirm the progressive reduction in Co peaks with the increase in laser power. The Co(111) peak completely disappears at nearly $1200 \mathrm{~W}$. This result matches very well what happens on MP treated samples, which are characterized by sharp WC peaks with Co peaks completely removed as result of the chemical etching [23].

After laser processing at $1400 \mathrm{~W}$ and over, it is also possible to note the formation of a brittle ternary eutectic phase of $W, C o$ and $C$ (often referred to as $\eta$ phase). The formation the $\eta$ phase can be ascribed to the 'local' carbon deficiency in the WC-Co, due to the precipitation of C from WC at high temperature (Eq. 1) [48-49]. $\eta$ phase can exist in both $M_{6} C$ and $M_{12} C$ forms. In the case of laser processing, the presence of $\mathrm{M}_{6} \mathrm{C}$ ranging from $\mathrm{Co}_{3.2} \mathrm{~W}_{2.8} \mathrm{C}$ to $\mathrm{Co}_{2} \mathrm{~W}_{4} \mathrm{C}$ is more probable due to the rapid cooling rate [48]. Indeed, the mechanical properties of WC-Co can be partially compromised by the presence of the brittle $\eta$ phase and its presence imposes an upper limit to the maximum laser power, whilst the residual presence of Co in the outermost layer imposes a lower limit to the minimum laser power. This leads to the identification of the best window of laser power for processing WC-Co substrates as falling in the range 1200-1300 W. Such a process window is a good compromise between the need for the selective removal of Co and the need to avoid the formation of brittle $\eta$ phase or of the birth of thermally altered large or melted WC grains or agglomerates. 
Fig. 9 shows the $\mathrm{WC}(100)$ peak vs. laser power, whilst Table 2 reports the corresponding shifts and full-widths at half-maximum (FWHM). The broad WC diffraction peaks of as-ground hardmetal substrates can be ascribed to lattice disorder, damage and micro-strains induced by the grinding process [50-51]. After laser processing, the FWHM of the WC (100) peak progressively decreased from $0.297 \pm 0.002$ to $0.113 \pm 0.002$ by increasing the laser power to $1500 \mathrm{~W}$. This finding, combined with the SEM observations after laser processing (Figs. 4b-4d), shows that recrystallization of the outermost layer of the WC, and consequent surface corrugation, can occur progressively by increasing the laser power. After laser processing, the heavily strained as-ground cemented carbides released part of their micro-strains and underwent the growth of tungsten carbide crystallites, which further contributed to the decrease of the peak FWHM. Both phenomena are promoted by the high energy density laser processing, which can locally bring the temperature to very high values, thus activating some sort of surface re-modelling. 


\section{Conclusions}

The present investigation concerned the application of a high power diode laser to thermally treating WC-Co substrates and making them prone to diamond coating by the CVD process. The following conclusions can be drawn:

- high power diode laser allows the selective removal of Co from the outermost layer of the WC-Co by local melting and vaporization in the surrounding of the hotter and better energy absorbing 'high melting and boiling point' WC.

- Three different classes of samples can be defined: (i) the under-treated one (i.e., laser power 600-1100 W), in which most of Co binder is selectively removed from the WC-Co surface, whilst WC grains are only slightly increased; (ii) the properly-treated one (i.e., laser power of 1200-1400 W), characterized by almost the full removal of Co binder from the WC-Co surface and by the further enlargement of WC grains, with the occasional formation of large grains or agglomerates; (iii) the over-treated one (i.e., laser power of $1500 \mathrm{~W}$ ), in which a complete surface reconstruction of the WC-Co is promoted, with the formation of new large WC grains resulting from the agglomeration of the starting small grains.

- The analysis of the phase transformation emphasizes: (i) the progressive disappearance of Co from the outermost layer of the WC-Co; (ii) the formation at high power of a ternary eutectic alloy of $W$, Co and $C$ ( $\eta$ phase).

- The mechanical properties of WC-Co can be partially compromised by the presence of the brittle $\eta$ phase. Its presence imposes an upper limit $(1300 \mathrm{~W})$ to the maximum laser power, whilst the residual presence of Co imposes a lower limit to the minimum laser power which should be used during laser processing (1200 W).

- Laser processing was found to relieve the micro-strains induced in the WC-Co substrate by the previous grinding process.

In conclusion, diode laser is able to selectively remove Co and make the WC-Co substrate prone to diamond coating by CVD process without any further chemical treatments. In fact, pulsed laser do not selectively remove Co. They only reduce Co concentration at the substrate surface by partial evaporation and recombination with the other constituents inside the material and produce a full reconstruction of the WC-Co and its corrugation. Therefore, further etching with acid solution is needed for dissolving the residual Co prior to diamond CVD. 


\section{Acknowledgements}

Dr. Marcheselli are kindly acknowledged for both the supply of the samples and the availability of the experimental apparatus. Dr. Polini is gratefully acknowledge for the useful suggestions and the stimulating insights. 


\section{References}

[1] Y.P. Ma, F.H. Sun, H.G. Xue, Z.M. Zhang, M. Chen, Diam. Relat. Mater. 16 (2007) 481

[2] R.F. Ávila, C. Godoy, A.M. Abrão, M.M. Lima, Wear 265 (2008) 49

[3] G.R. Santos, D.D. Costa, F.L. Amorim, R.D. Torres, Surf. Coat. Technol. 202 (2007) 1029

[4] R. Weissenbacher, R. Haubner, Int. J. Refract. Met. Hard Mater. 24 (2006) 374

[5] R. Polini, F. Casadei, P.D. Antonio, E. Traversa, Surf. Coat. Technol. 166 (2003) 127

[6] G. Cabral, J. Gäbler, J. Lindner, J. Grácio, R. Polini, Diam. Relat. Mater. 17 (2008) 1008

[7] J.P. Davim, F. Mata, Mater. Des. 29 (2008) 1568

[8] F.M. Cerio, J.A. Herb, R. Cummings, Surf. Coat. Technol. 62 (1993) 674

[9] K. Kanda, S. Takehana, S. Yoshida, F. Shikamura, K. Ishigane, in: M. Yoshikawa, M. Murakawa, Y.

Tzeng, W.A. Yarbrough (Eds.), 2nd Int. Conf. on the Application of Diamond Films and Relat.

Mater., MYU, Tokyo, 1993, p. 565

[10] P.W. May, Phil. Trans. R. Soc. Lond. A 358 (2000) 473; S. Ferro, J. Mater. Chem. 12 (2002) 2843

[11] H. Baker (Ed.), ASM Handbook, Vol. 3, Alloy Phase Diagrams, ASM International, Metals Park, Ohio, USA, 1997.

[12] X. Chen, J. Narayan, J. Appl. Phys. 74 (1993) 4168.

[13] K. Shibuki, M. Yagi, K. Saijo, S. Takatsu, Surf. Coat. Technol. 36 (1988) 295.

[14] T.H. Huang, C.T. Kuo, C.S. Chang, C.T. Kao, H.Y. Wen, Diam. Relat. Mater. 1 (1992) 594.

[15] F.-M. Pan, J.-L. Chen, T. Chou, T.-S. Lin, L. Chang, J. Vac. Sci. Technol., A 12 (1994) 1519.

[16] A. Inspektor, C.E. Bauer, E.J. Oles, Surf. Coat. Technol. 68-69 (1994) 359.

[17] S. Kubelka, R. Haubner, B. Lux, R. Steiner, G. Stingeder, M. Grasserbauer, Diam. Films Technol. 5 (1995) 105.

[18] J. Oakes, X.X. Pan, R. Haubner, B. Lux, Surf. Coat. Technol. 47 (1991) 600.

[19] M.A. Taher, W.F. Schmidt, W.D. Brown, S. Nasrazaani., H.A. Naseem, A.P. Malshe, Surf. Coat. Technol. 86/87 (1996) 678.

[20] A.K. Mehlmann, A. Fayer, S.F. Dirnfeld, Y. Avigal, R. Porath, A. Kochman, Diam. Relat. Mater. 2 (1993) 317.

[21] P.X. Ling, G.Z. Ping, Thin Solid Films 239 (1994) 47.

[22] C. Tsai, J.C. Nelson, W.W. Gerberich, J. J.Herbelein, E. Pfender, Diam. Relat. Mater. 2 (1993) 617.

[23] M.G. Peters, R.H. Cummings, European Patent 0519587 A1 (1992). 
[24] F. Deuerler, H. van den Berg, R. Tabersky, A. Freundlieb, M. Pies, V. Buck, Diam. Relat. Mater. 5 (1996) 1478.

[25] C.R. Lin, C.T. Kuo, R.M. Chang, Thin Solid Films 308- 309 (1997) 273.

[26] N. Kikuchi, T. Komatsu, H. Yamashita, H. Yoshimura, US Patent 4,731,296 (1988).

[27] I. Endler, A. Leonhardt, H.-J. Scheibe, R. Born, Diam. Relat. Mater. 5 (1996) 299.

[28] M. Nesladek, J. Spinnewyn, C. Asinari, R. Lebout, R. Lorent, Diam. Relat. Mater. 3 (1993) 98.

[29] E. Cappelli, F. Pinzari, P. Ascarelli, G. Righini, Diam. Relat. Mater. 5 (1996) 292.

[30] C.R. Lin, C.T. Kuo, R.M. Chan, Diam. Relat. Mater. 7 (1998) 1628.

[31] W.D. Fan, X. Chen, K. Jagannadham, J. Narayan, J. Mater. Res. 9 (1994) 2850.

[32] J.K. Wright, R.L. Williamson, K.J. Maggs, Mater. Sci. Eng., A Struct. Mater.: Prop. Microstruct. Process. 187 (1994) 87.

[33] S. Silva, V.P. Mammana, M.C. Salvadori, O.R. Monteiro, I.G. Brown, Diam. Relat. Mater. 8 (1999) 1913.

[34] C. Faure, W. Hanni, C. Julia Schmutz, M. Gervanoni, Diam. Relat. Mater. 8 (1999) 830.

[35] R. Polini, F. Pighetti Mantini, M. Barletta, R. Valle, F. Casadei, Diam. Relat. Mater., 15 (2006) $1284-1291$

[36] R. Polini, M. Barletta, Diam. Relat. Mater., 17 (2008) 325-335

[37] R. Polini, M. Barletta, M. Delogu, Thin Solid Films 515 (2006) 87-94

[38] Z. Xu, L. Lev, M. Lukitsch, A. Kumar, Diam. Relat. Mater., 16 (2007) 461-466

[39] K. Saijo, M. Yagi, K. Shibuki, S. Takatsu, Surf. Coat. Technol. 47 (1991) 646.

[40] Z.M. Zhang, X.C. He, H.S. Shen, F.H. Sun, M. Chen, Y.Z. Wan, Diam. Relat. Mater. 9 (2000) 1749.

[41] E.J. Oles, A. Inspektor, C.E. Bauer, Diam. Relat. Mater. 5 (1996) 617.

[42] R. Polini, F. Bravi, F. Casadei, P. D’Antonio, E. Traversa, Diam. Relat. Mater. 11 (2002) 726.

[43] R. Polini, G. Marcheselli, E. Traversa, J. Am. Ceram. Soc. 77 (1994) 2043.

[44] R.V. Singh, D.R. Gilbert, J. Fitz-Gerald, S. Harkness, D.G. Lee, Science 272 (1996) 396.

[45] T. Li, Q. Lou, J. Dong, Y. Wei, J. Zhou, J. Liu, Z. Zhang, F. Sun, Appl. Surf. Sci. 193 (2002) 102- 
[46] T. Li, Q. Lou, J. Dong, Y. Wei, J. Liu, Appl. Surf. Sci. 172 (2001) 331-344

[47] G. Dumitru, B. Luscher, M. Krack, S. Bruneau, J. Hermann, Y. Gerbig, Int. J. Refract. Met. H., 23 (2005) 278-286

[48] C.P. Paul, A. Khajepour, Opt. Laser Technol. 40 (2008) 735-741

[49] R. Polini, Thin Solid Films 515 (2006) 4-13

[50] R. Polini, P. D’Antonio, E. Traversa, Diam. Relat. Mater. 12 (2003) 340.

[51] J.B.J.W. Hegeman, J.Th.M. De Hosson, G. deWith, Wear 248 (2001) 187. 
List of Tables

\begin{tabular}{|l|c|c|c|}
\hline Properties & Unit & WC & Co \\
\hline Density & $\mathrm{kg} / \mathrm{m}^{3}$ & 15800 & 8900 \\
\hline Melting point & $\mathrm{K}$ & 3243 & 1768 \\
\hline Boiling point & $\mathrm{K}$ & 6143 & 3200 \\
\hline Thermal conductivity & $\mathrm{W} /(\mathrm{mK})$ & 84 & 100 \\
\hline Coefficient of thermal expansion & $\mathrm{m} /(\mathrm{mK})$ & 4.3 & 14 \\
\hline Hardness & $\mathrm{HRA}$ & 93 & 67 \\
\hline Absorption Coefficient @NIR (1.0 $\mu \mathrm{m})$ & - & $\sim 0.8$ & $\sim 0.55$ \\
\hline
\end{tabular}

Table 1.

\begin{tabular}{|c|c|c|}
\hline Sample & $\mathbf{x}_{c}$, degree & $\begin{array}{c}\text { peak width (FWHM), } \\
\text { degree }\end{array}$ \\
\hline WC-Co as received & $35.631 \pm 6.2 \mathrm{E}-4$ & $0.297 \pm 0.002$ \\
\hline $\mathbf{8 0 0} \mathbf{~ W}$ & $35.681 \pm 4.2 \mathrm{E}-4$ & $0.263 \pm 0.001$ \\
\hline $\mathbf{9 0 0} \mathbf{W}$ & $35.671 \pm 4.39 \mathrm{E}-4$ & $0.214 \pm 0.001$ \\
\hline $\mathbf{1 0 0 0} \mathbf{W}$ & $35.675 \pm 5.72 \mathrm{E}-4$ & $0.187 \pm 0.002$ \\
\hline $\mathbf{1 1 0 0} \mathbf{W}$ & $35.672 \pm 6.11 \mathrm{E}-4$ & $0.177 \pm 0.002$ \\
\hline $\mathbf{1 2 0 0} \mathbf{W}$ & $35.666 \pm 6.04 \mathrm{E}-4$ & $0.146 \pm 0.002$ \\
\hline $\mathbf{1 3 0 0} \mathbf{W}$ & $35.666 \pm 5.94 \mathrm{E}-4$ & $0.143 \pm 0.002$ \\
\hline $\mathbf{1 4 0 0} \mathbf{W}$ & $35.642 \pm 5.96 \mathrm{E}-4$ & $0.142 \pm 0.002$ \\
\hline $\mathbf{1 5 0 0} \mathbf{W}$ & $35.651 \pm 7.35 \mathrm{E}-4$ & $0.113 \pm 0.002$ \\
\hline
\end{tabular}

Table 2. 


\section{List of Captions}

Table 1. Thermo-physical properties of WC-Co and Co (data taken from www.matweb.com and [48])

Table 2. Peak position and peak width of the WC(100) peaks shown in Fig. 9 obtained from fitting with the Lorentzian peak function. Experimental uncertainties are given.

Figure 1. SEM surface pictures of the WC-Co substrate before and after laser processing: (a) asreceived WC-Co; (b) after $600 \mathrm{~W}$ laser processing; (c) after $800 \mathrm{~W}$ laser processing; (d) after $900 \mathrm{~W}$ laser processing; (e) after $1000 \mathrm{~W}$ laser processing; (f) after $1100 \mathrm{~W}$ laser processing; (g) after 1200 W laser processing; (h) after $1300 \mathrm{~W}$ laser processing; (i) after $1400 \mathrm{~W}$ laser processing.

Figure 2. Surface profiles of as-received, MP-treated and laser-treated WC-Co substrates.

Figure 3. Average roughness $R_{a}$ of as-received, MP-treated and laser-treated $(900,1300$ and 1500 W) WC-Co substrates.

Figure 4. SEM micrographs of WC-Co substrate before and after laser processing: (a) as-received WC-Co; (b) under-treated laser samples; (c) properly-treated laser samples; (d) over-treated laser samples; (e) MP-treated samples.

Figure 5. SEM micrographs of WC-Co substrate and W-rich droplets after high energy density laser processing.

Figure 6. EDX spectra of W-rich droplets and WC grains after laser processing at $1500 \mathrm{~W}$.

Figure 7. $\theta / 2 \theta \mathrm{X}$-ray diffractograms of as-received, MP-treated and laser-treated WC-Co substrates. Peaks are indexed.

Figure 8. Grazing incidence $\left(\omega=3^{\circ}\right) \mathrm{X}$-ray diffractograms of as-received, MP-treated and lasertreated WC-Co substrates. Peaks are indexed. 
Figure 9. High resolution $\theta / 2 \theta \mathrm{X}$-ray diffractograms of the $\mathrm{WC}(100)$ peak of the as-received, MPtreated and laser-treated WC-Co substrates. 


\section{List of Figures}

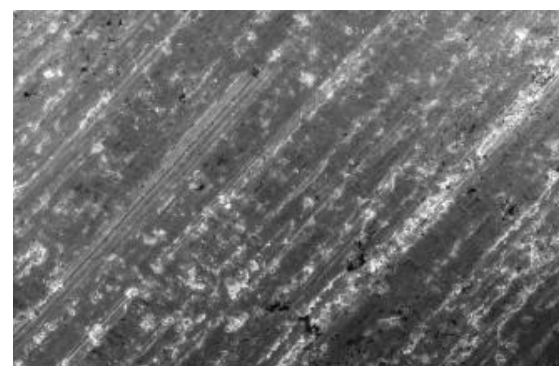

(a)

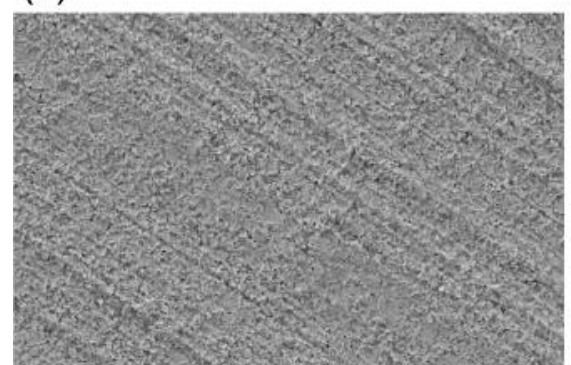

(d)

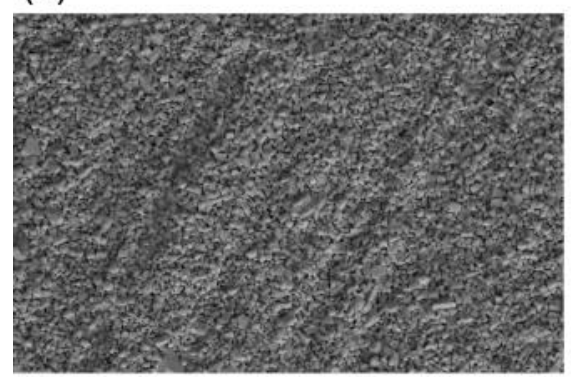

(g)

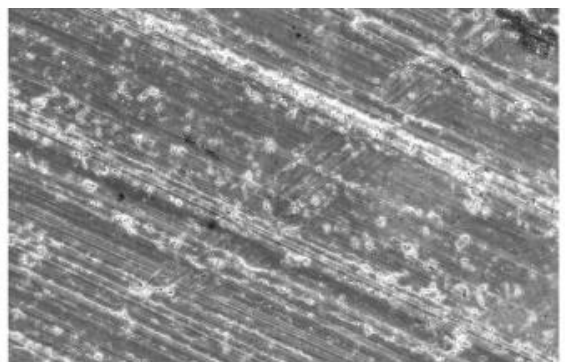

(b)

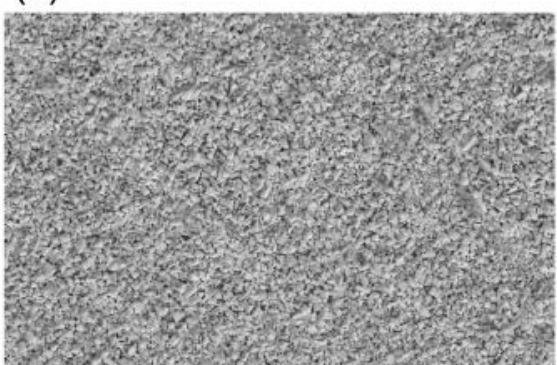

(e)

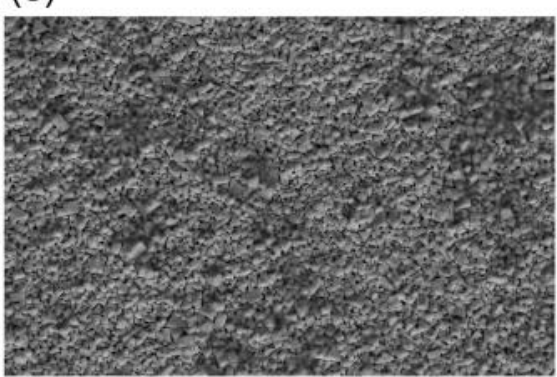

(h)

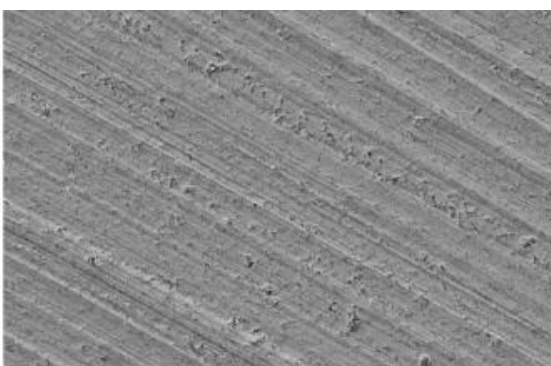

(c)

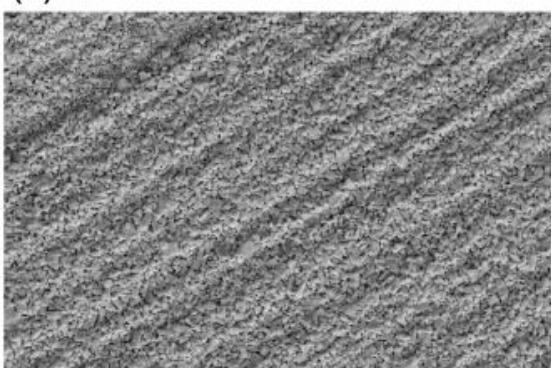

(f)

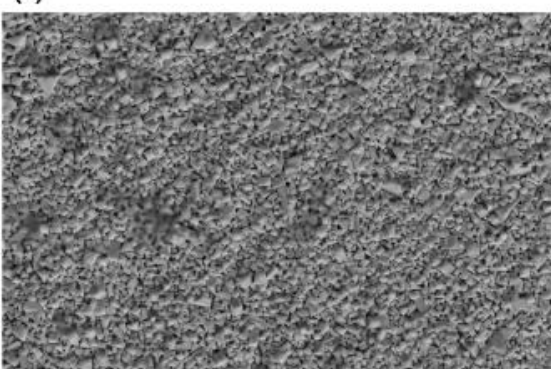

(i)
$20 \mu \mathrm{m}$

Figure 1 


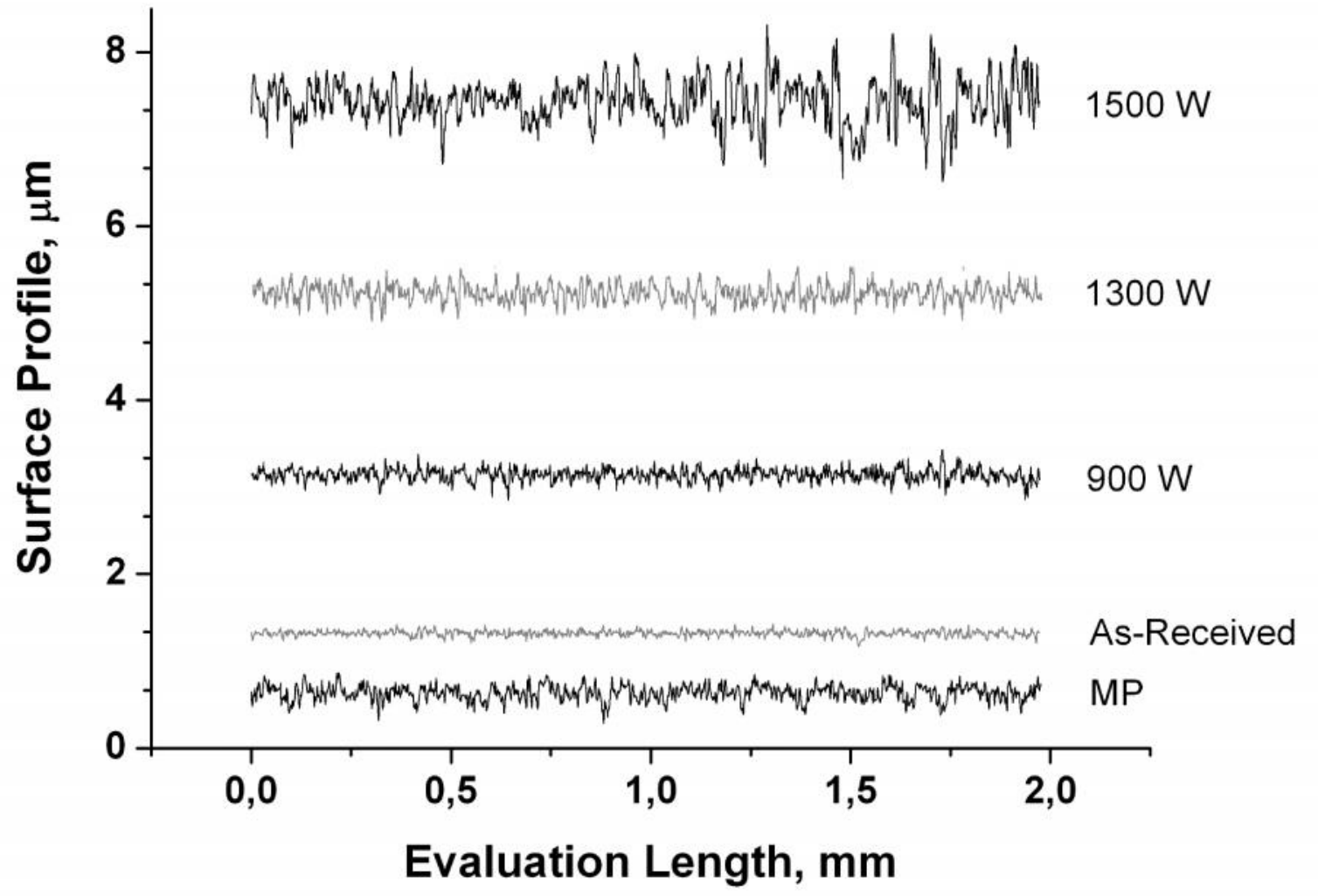

Figure 2 


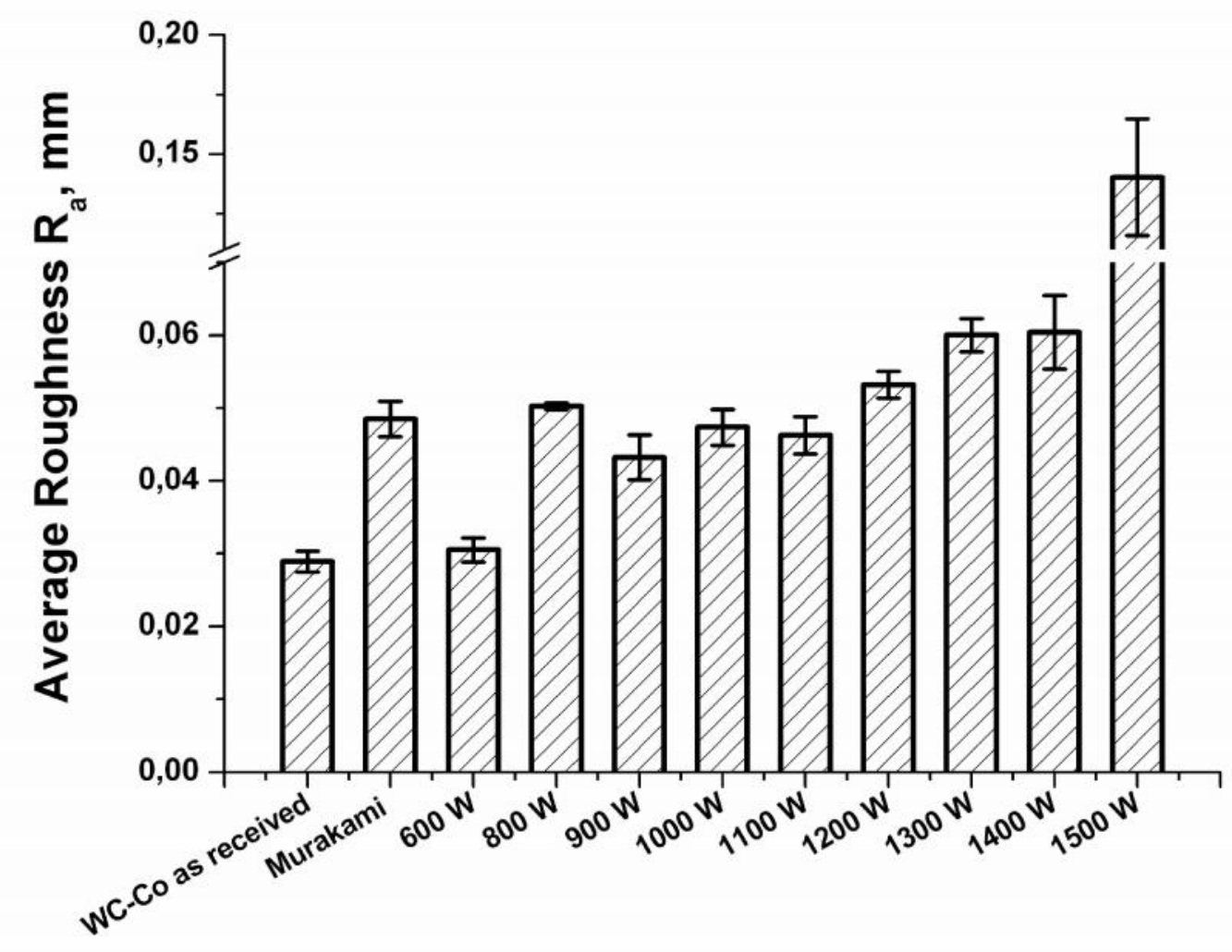

Figure 3 

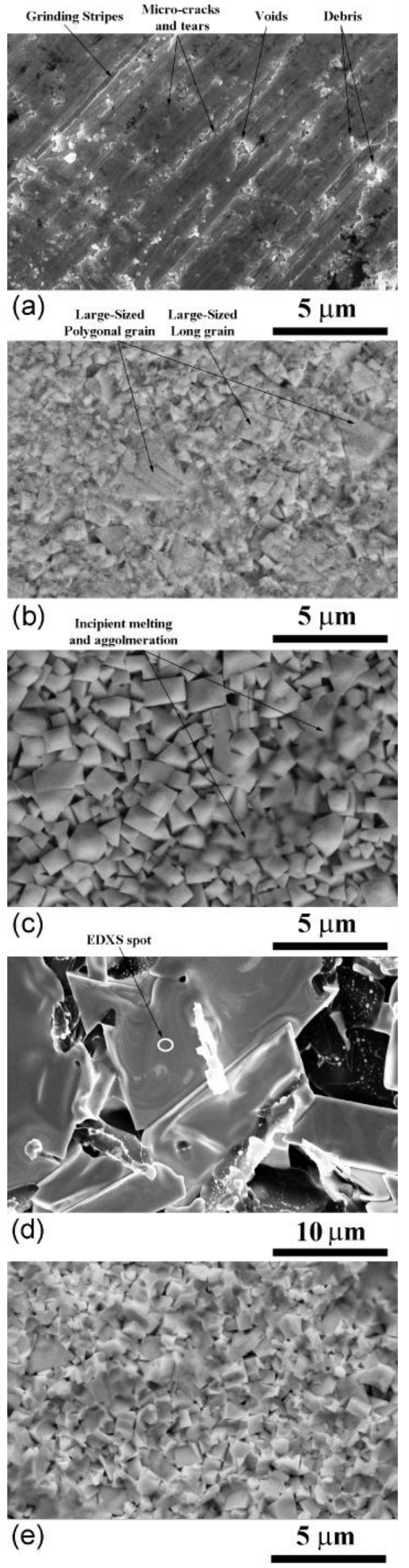

Figure 4 


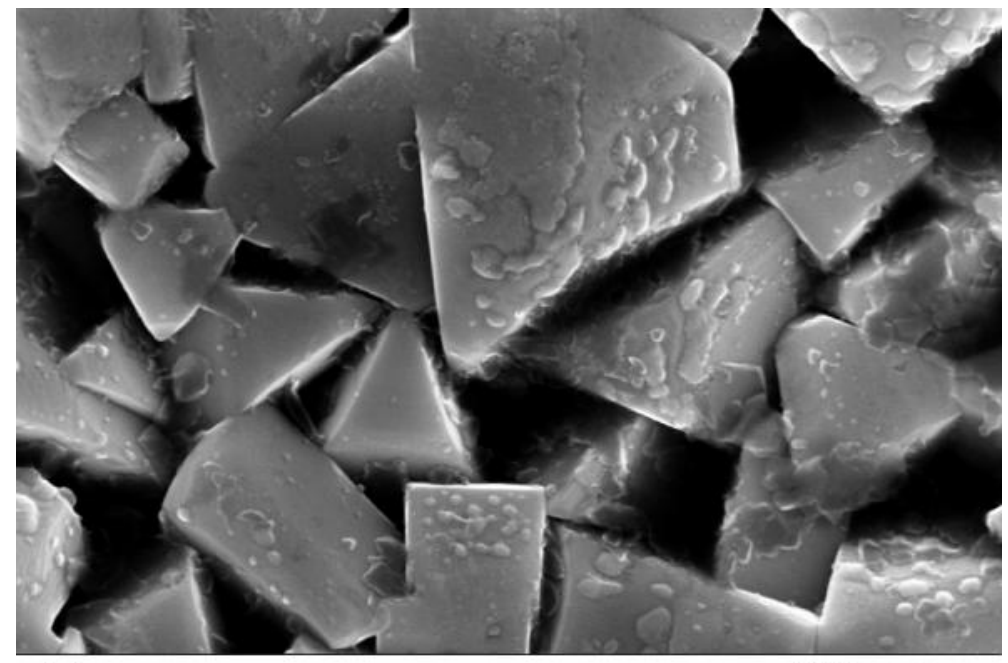

(a)

$500 \mathrm{~nm}$

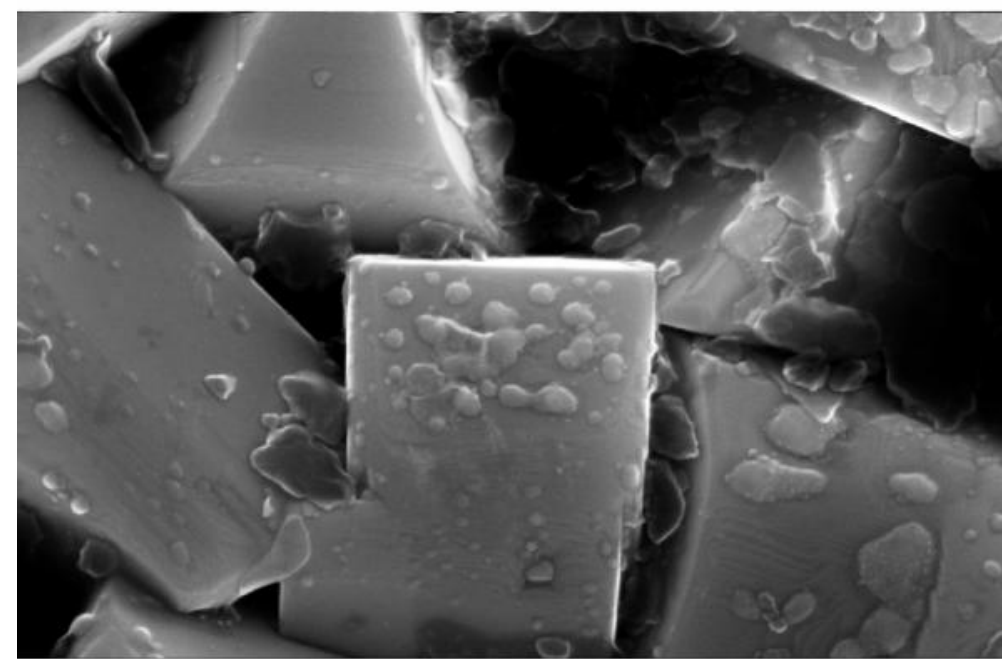

(b)

$250 \mathrm{~nm}$

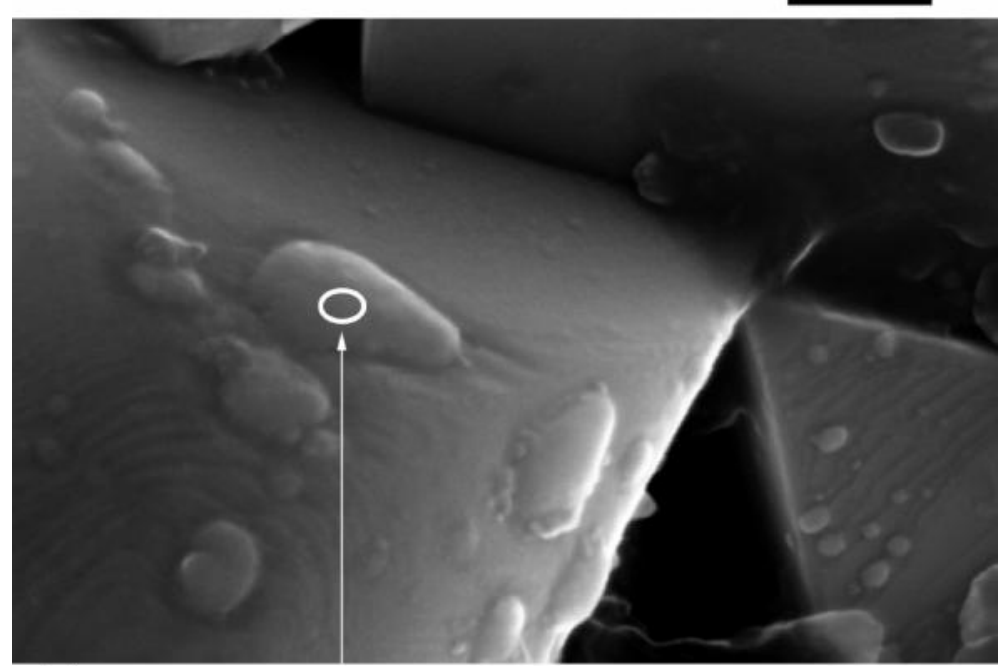

(c) EDXS Spot

$100 \mathrm{~nm}$

Figure 5 


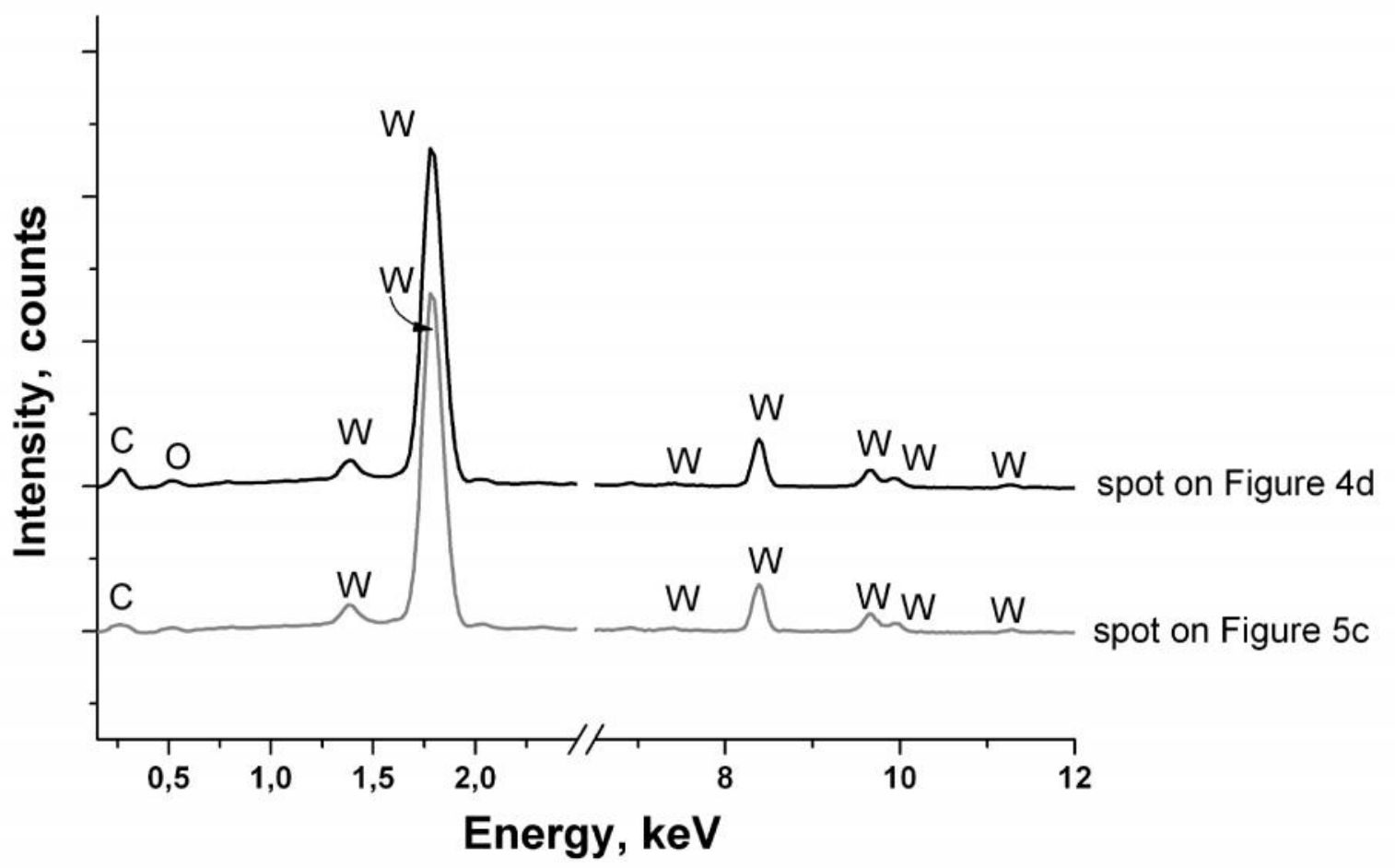

Figure 6 


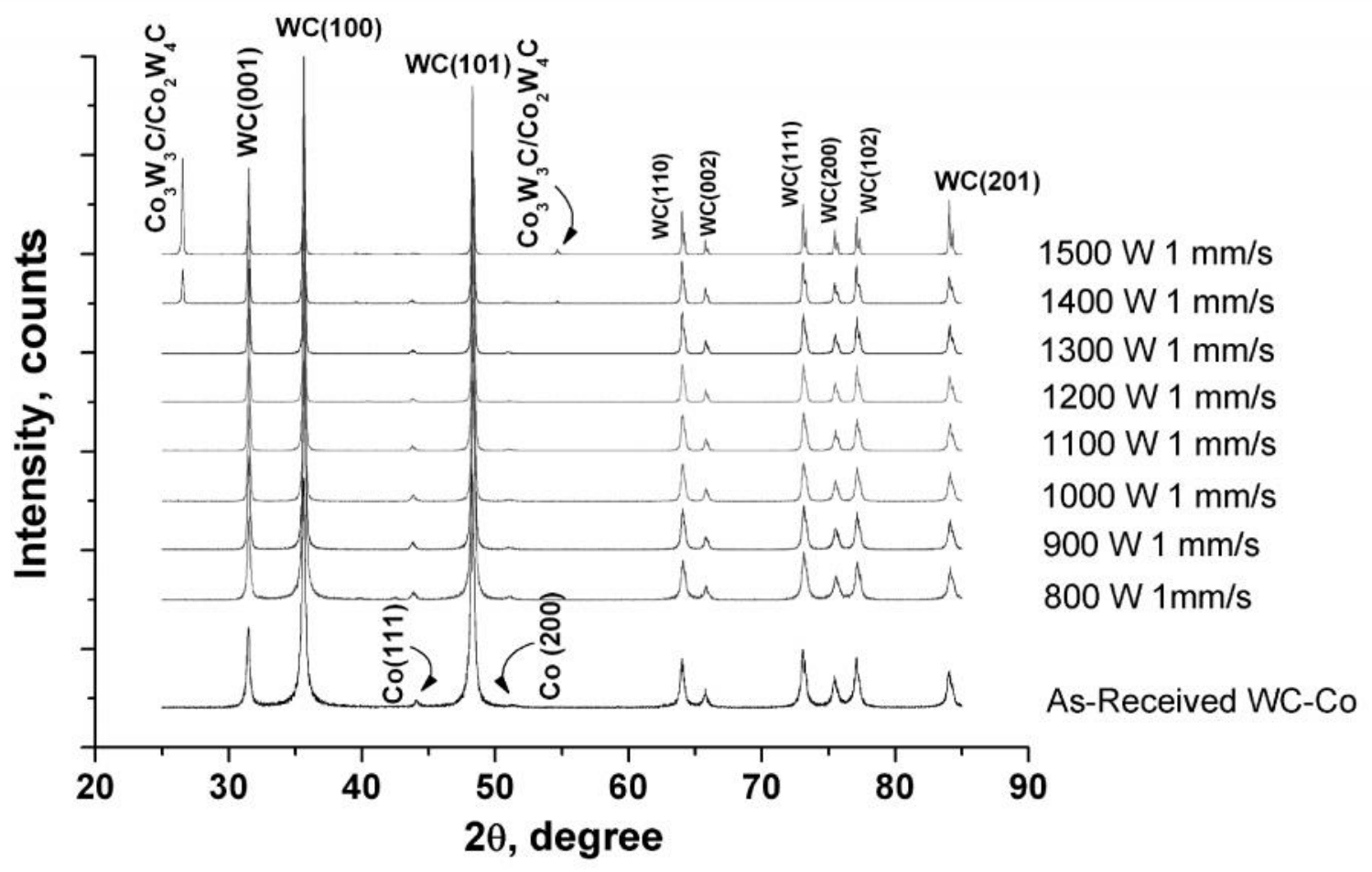

Figure 7

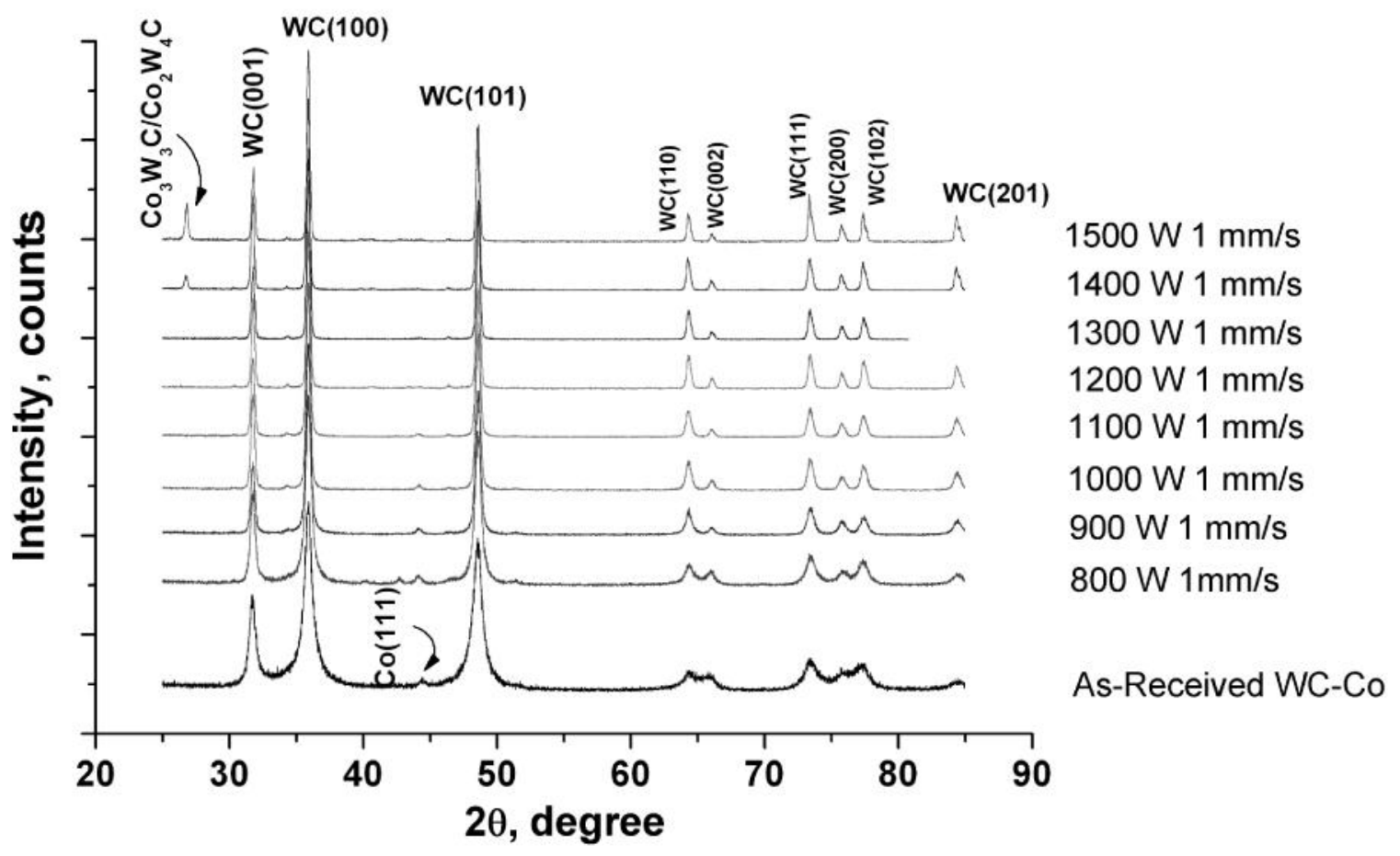

Figure 8 


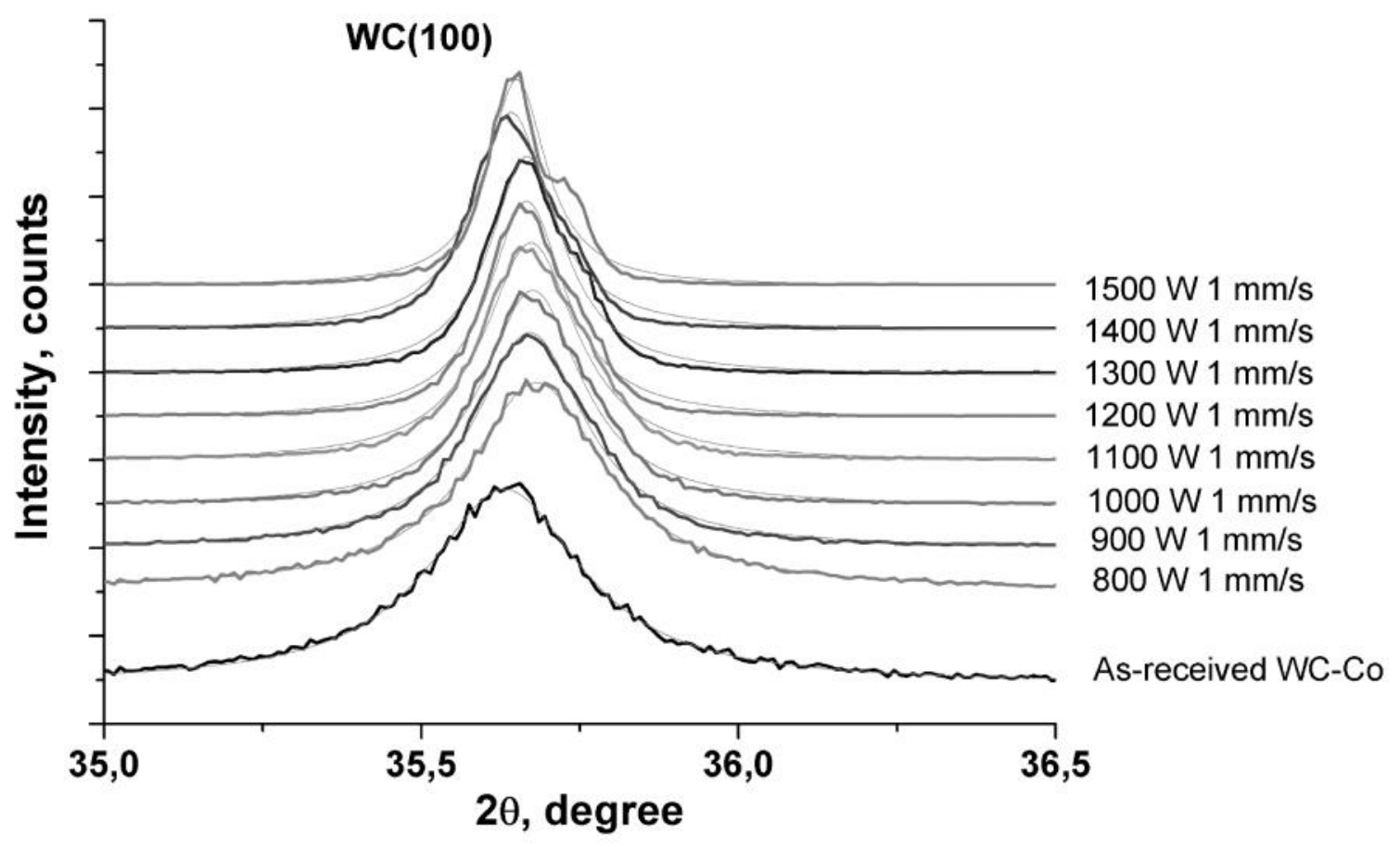

Figure 9 